\author{
Maristela Müller ${ }^{1}$
}

\title{
Pós-graduação em Artes Visuais e a formação de professores(as) no sul do Brasil
}

Postgraduate studies in Visual Arts and teacher training in southern Brazil

Posgrado en Artes Visuales y formación de profesores en el sur de Brasil 


\section{Resumo}

Neste artigo, o objeto de estudo é a formação de professores(as), no contexto dos Programas de Pós-Graduação em Artes Visuais, das instituições públicas localizadas no Sul do Brasil e que ofertam o doutorado e/ou mestrado acadêmico. Foram coletados 430 estudos, desenvolvidos por estudantes da pós-graduação, no recorte temporal de 2014 a 2019, junto aos programas: PPGAV da UFRGS, PPGAV da UDESC, PPGArt da UFSM e PPGAVI da UFPEL, a fim de compreender como a produção das teses e dissertações revelam as problemáticas vivenciadas na pós-graduação em artes visuais, na perspectiva da formação de professores(as). As teses e dissertações revelam, entre outras coisas, a necessidade de se estudar a formação de professores: pela falta de pesquisas sobre o tema na pós-graduação; pelos ataques constantes a área de artes visuais e a recorrente ameaça de remoção das artes do currículo escolar; para atuar coletivamente contra a precarização da educação, contra a formação aligeirada e evitar o desmonte da educação. Como aporte teórico, metodológico e pedagógico referencia-se o Materialismo Histórico-Dialético (MHD), desenvolvido por Karl Marx (1978; 1985; 1998) e a Pedagogia Histórico-Crítica (PHC), concebida por Dermeval Saviani (1984; 2009; 2013; 2018; 2019). Reforça-se a necessidade de realizar ações concretas que viabilizam a práxis educativa nas artes visuais e ações que ampliem o debate sobre a formação de professores. Pois, no Brasil, as pessoas não atuam unicamente como pesquisadores, atuam conjuntamente na docência nas IES, nas escolas, bem como, no ensino informal em espaços culturais.

Palavras-chave: Formação de Professores(as); Pós-Graduação; Artes Visuais; Observatório; Pedagogia Histórico-Crítica.

\section{Abstract}

In this research, the object of study on which it is based is the training of teachers, in the context of Postgraduate Programs in Visual Arts of public institutions in southern Brazil, which offer the Doctorate and/or Master's Degree. Data were collected, together with the programs, in order to understand how the production of theses and dissertations reveal the problems experienced in graduate studies in Visual Arts from the perspective of teacher training. To substantiate this reflection, 430 surveys were collected, in the period between 2014 and 2019, in the PPGAV of UFRGS, PPGAV of UDESC, PPGArt of UFSM, and PPGAVI of UFPEL. Among other things, theses and dissertations reveal the need to study teacher training in Brazil due to: lack of research on this subject in postgraduate studies; the constant attacks on the Visual Arts area and the recurrent threat of removal of the Arts subject from the school curriculum;

1 Professora colaboradora da UDESC. E-mail: maristela.muller@udesc.br. Lattes: http://lattes.cnpq. br/6851046588756371. ORCID: https://orcid.org/0000-0002-0649-9813. 
to establish an opinion in face of a rushed formation; act against precariousness and avoid the dismantling of education. As theoretical, methodological, and pedagogical support, a reference is made to the Historical-Dialectical Materialism developed by Karl Marx $(1978 ; 1985 ; 1998)$ and the Historical-Critical Pedagogy conceived by Dermeval Saviani $(1984 ; 2009 ; 2013 ; 2018 ; 2019)$. It reinforces the need to carry out concrete actions that make educational praxis in the visual arts viable and actions that broaden the debate on teacher education. Because, in Brazil, people do not act only as researchers, they act together in teaching in universities, in schools, as well as in informal teaching in cultural spaces.

Keywords: Teacher Training; Postgraduate Studies; Visual Arts; Observation; Historical-Critical Pedagogy.

\section{Resumen}

En este artículo, el objeto de estudio es la formación de docentes, en el contexto de Programas de Posgrado en Artes Visuales, en instituciones públicas ubicadas en el sur de Brasil, que ofrecen títulos de doctorado y/o maestría académica. Se recopilaron 430 estudios, desarrollados por estudiantes de posgrado, en el período de 2014 a 2019, junto con los programas: PPGAV de UFRGS, PPGAV de UDESC, PPGArt de UFSM y PPGAVI de UFPEL, con el fin de comprender cómo la producción de tesis y disertaciones revelan la problemática vivida en los estudios de posgrado en artes visuales, desde la perspectiva de la formación del profesorado. Las tesis y disertaciones revelan, entre otras cosas, la necesidad de estudiar la formación del profesorado: debido a la falta de investigación sobre el tema en los estudios de posgrado; por los constantes ataques al campo de las artes visuales y la amenaza recurrente de eliminar las artes del currículo escolar; actuar colectivamente contra la precariedad de la educación, contra la formación aligerada y evitar el desmantelamiento de la educación. Como soporte teórico, metodológico y pedagógico, se hace referencia al Materialismo Histórico-Dialéctico (MHD), desarrollado por Karl Marx (1978; 1985; 1998) y a la Pedagogía Histórico-Crítica (APS), concebida por Dermeval Saviani (1984; 2009; 2013; 2018; 2019). Se refuerza la necesidad de realizar acciones concretas que viabilicen la praxis educativa en las artes visuales y acciones que amplíen el debate sobre la formación docente. Porque, en Brasil, las personas no actúan solo como investigadores, actúan en conjunto en la docencia en las universidades, en las escuelas, así como en la docencia informal en los espacios culturales.

Palabras clave: Formación de profesores; Posgraduación; Artes visuales; Observatorio; Pedagogía histórico-crítica. 


\section{Introdução}

Neste artigo, apresenta-se um recorte da tese de doutorado (MÜLLER, 2021), produzida na linha de pesquisa denominada Ensino das Artes Visuais, do Programa de Pós-Graduação em Artes Visuais (PPGAV), da Universidade do Estado de Santa Catariana (UDESC) ${ }^{2}$. A pesquisa também está vinculada ao Observatório da Formação de Professores no âmbito do Ensino de Artes: estudos comparados entre o Brasil e a Argentina (OFPEA/BRARG) ${ }^{3}$.

\section{Sobre a pesquisa e o referencial teórico}

Ao longo do estudo desenvolvido, realizou-se debates teóricos e a análise dos dados, com o intuito de dar sustentação a pesquisa. A teoria pedagógica que embasa a concepção de ensino, educação e a formação de professores é a Pedagogia Histórico-Crítica (PHC). Corrente pedagógica criada na década de 1980 por Dermeval Saviani $(1984 ; 2013 ; 2018 ; 2019)$, na qual compreende-se a educação como um fenômeno próprio dos seres humanos e que está relacionada com a categoria trabalho, como mediadora do processo de humanização ao longo de toda a história.

A educação, na perspectiva da PHC, visa o desenvolvimento humano ao oportunizar, nas relações de ensino e aprendizagem, o acesso as produções mais ricas da humanidade, por meio do saber sistematizado nas escolas. Uma educação voltada para os filhos(as) da classe trabalhadora (proletariado), levando em consideração o interesse dos dominados, já que o conhecimento lhes foi sonegado ao longo da maior parte da história (mesmo quando produzido pela classe trabalhadora), estando disponível principalmente para a classe dominante, que detinha e detêm o capital econômico e cultural.

Em consonância, compreende-se o trabalho educativo como "o ato de produzir direta e intencionalmente, em cada indivíduo singular, a humanidade que é produzida histórica e coletivamente pelo conjunto dos homens" (SAVIANI, 2013, p.

2 Tese orientada pela Professora Doutora Maria Cristina da Rosa Fonseca da Silva.

3 O projeto OFPEA/BRARG recebeu, nos anos de 2011 a 2013, financiamento da Coordenação de Aperfeiçoamento de Pessoal de Nível Superior (CAPES-Brasil) e do Ministerio de Ciencia, Tecnología e Innovación Productiva (MINCYT-Argentina) pelo Programa de Cooperação Científico e Tecnológico Argentino-Brasileiro (CAPES-MINCYT). Mesmo não havendo mais o apoio financeiro desses órgãos, o projeto segue com a realização de pesquisas produzidas por estudantes da graduação, mestrado, doutorado e professores(as) em diferentes universidades do Brasil e da Argentina, como a Universidade do Estado de Santa Catarina (UDESC), Universidade Federal de Santa Maria (UFSM), Instituto Federal de Santa Catarina (IFSC) campus Xanxerê, Universidade Federal do Paraná (UFPR), Universidade Estadual de Ponta Grossa (UEPG), Instituto Federal do Paraná (IFP) campus avançado Coronel Vivida, Universidade Federal do Espírito Santo (UFES), Universidade Federal do Mato Grosso do Sul (UFMS), Universidade Federal do Sul da Bahia (UFSB), Universidade Federal do Oeste da Bahia (UFOB), Universidade Federal do Recôncavo da Bahia (UFRB), Universidade Federal do Vale do São Francisco (UNIVASF), Universidade Federal do Maranhão (UFMA), Universidade Federal de Roraima (UFRR) e Universidade Federal do Amazonas (UFAM), a Universidad Nacional de las Artes (UNA) e a Universidad Nacional de Rosario (UNR). Para acessar o site o do Observatório basta clicar no link: https://observatorioformacaoarte.org/ e conhecer os(as) pesquisadores(as), os eventos realizados e as pesquisas publicadas na perspectiva de mapear, debater e divulgar a formação de professores e fortalecer o ensino de artes. 
13). Significa dizer que o ensino é uma ação consciente realizada pelos(as) professores(as) em um determinado contexto, com o objetivo de contribuir para o constante processo de humanização dos(as) estudantes, pela via do acesso ao saber sistematizado, daquilo que foi produzido histórica e socialmente e que se relaciona com a prática social atual.

No contexto da educação brasileira, entre suas contradições e limites, tem-se a consciência de que a educação possui seu poder. Na concepção de educação, utilizada na PHC, luta-se para que todas as pessoas tenham igualmente acesso ao saber e o poder da educação está em desenvolver seres humanos conscientes e atuantes na sociedade, com o intuito de tentar superar a sociedade capitalista que aliena e oprime. Tendo, ao mesmo tempo, a consciência de que se trata de um poder limitado, pois a educação está vinculada as demais esferas da sociedade e, para haver uma mudança real, é necessário atuar coletivamente.

Ao longo deste estudo, a PHC foi referenciada para se falar sobre o ensino e a educação brasileira na relação com o contexto e a especificidade das artes visuais. A PHC está fundamentada no Materialismo Histórico-Dialético, desenvolvido por Karl Marx (1978; 1985; 1998), que também embasou esta pesquisa, teórica e metodologicamente, ao longo da coleta e análise dos dados. Nesta perspectiva, a pesquisa partiu de um objeto concreto, que foi constantemente questionado e analisado, a fim de compreendê-lo em suas múltiplas determinações e em suas contradições.

Nas reflexões acerca da formação de professores e a relação com a criação da pós-graduação no Brasil, desvelou-se 3 eixos que dão base para refletir as problemáticas enfrentadas. No eixo 1 - explicita-se o começo da pós-graduação como uma tradição inventada (ALMEIDA, 2017); no eixo 2 - destaca-se o dilema produtividade e qualidade; e no eixo 3 - identifica-se o dilema da formação didático-pedagógico e dos conteúdos culturais-cognitivos (SAVIANI, 2009). Sendo que, nestes eixos, reverberam uma série de outras problemáticas relacionados a formação de professores, que devido aos limites de um artigo, não serão problematizadas neste momento.

Focando nos dados, foram encontrados 430 estudos, entre eles 77 teses e 353 dissertações, produzidas nos quatro programas: o PPGAV da UFRGS, o PPGAV da UDESC, PPGArt da UFSM e o PPGAVI da UFPEL, de 2014 a 2019. A partir deste levantamento foram analisados os temas mais pesquisados na pós-graduação (a partir do título, do resumo e das palavras-chave das teses e dissertações), em quais linhas as pesquisas foram produzidas, os artistas citados nos títulos, as técnicas enfatizadas nos processos artísticos, assim como, as pesquisas voltadas para o ensino de artes visuais e a formação de professores.

$\mathrm{Na}$ análise dos dados percebeu-se que a maior produção de teses e dissertações se concentra nos processos artísticos ou poéticas, ou seja, na reflexão sobre a produ-

4 Diz-se estudos "encontrados", pois não se descarta a possibilidade de alguma tese e/ou dissertação ter ficado de fora da coleta de dados, mesmo tendo o cuidado de triangular os dados coletados em diferentes abas dos portais institucionais, das bibliotecas institucionais e da BDTD. 
ção artística dos próprios pesquisadores e pesquisadoras. Um dos motivos para este volume de produções está no fato de que há uma linha de pesquisa voltada para os processos artísticos ou poéticas em todos os quatro programas do Sul do Brasil.

Em outra etapa da pesquisa, buscou-se aprofundar a análise do corpo das teses e dissertações, selecionadas do computo geral, voltadas para as linhas de pesquisa sobre educação e ensino artes visuais. Os dois Programas que contemplam uma linha voltada para o ensino e educação são: o PPGAV da UFPEL, com a linha chamada Educação em Artes e Processos de Formação Estética; e o PPGAV da UDESC, com a linha chamada Ensino das Artes Visuais.

Seguindo critérios específicos, como: 1ำ critério - dissertações e teses que tratam do ensino formal (não foram selecionados associações, oficinas não escolares, workshop, arte em comunidade, ateliê e espaços culturais); e $2^{\circ}$ critério - dissertações e teses que abordam o ensino de artes visuais com conteúdo de artes visuais. A partir destes dois critérios, selecionou-se 40 pesquisas voltadas para o ensino formal de artes visuais. Dentre estas, realizou-se um novo recorte a partir de mais um critério de seleção: 3 o critério - dissertações e teses cujo foco concentra-se na formação de professores(as) ou formação continuada de professores(as) de artes visuais. Assim, chegou-se a 14 estudos (2 teses e 12 dissertações) que debatem especificamente a formação de professores de artes visuais e a atuação no ensino formal.

Na etapa seguinte, investigou-se a formação acadêmica e atuação na docência das 430 pessoas que produziram as 430 teses e dissertações, analisadas anteriormente, e que concluíram a pós-graduação de 2014 a 2019. Buscou-se informações específicas sobre o currículo dos pesquisadores(as) na Plataforma Lattes, com o intuito de compreender se as pessoas que cursaram mestrado e doutorado atuam ou atuaram como professores e se cursaram ou não a licenciatura em sua formação inicial. Esta nova coleta de dados se justifica, no sentido de que, se as pessoas estão atuando como professores(as) e não cursaram licenciatura na formação inicial a responsabilidade da pós-graduação se amplia frente ao ensino e a formação de professores.

Por meio desta pesquisa reforça-se a necessidade de realizar ações concretas que viabilizam a práxis educativa nas Artes Visuais. Pois, no Brasil, as pessoas não atuam unicamente como pesquisadores, atuam conjuntamente na docência nas IES, assim como atuam nas escolas e ministram aulas/cursos no ensino informal e em espaços culturais. Então, o ensino e a formação de professores não podem ser negligenciados na pós-graduação. Visto que, a formação de professores(as) realizada em instituições públicas pode ser um espaço de formação de intelectuais orgânicos, em uma perspectiva crítica e contra-hegemônica, para atuar nas escolas e universidades, na construção de conhecimentos e com compromisso social. 


\section{O que os dados revelam}

Passando para a sistematização e análise dos dados coletados nos quatro programas de pós-graduação de artes visuais do Sul do Brasil, referente aos estudos concluídos nos anos de 2014 a 2019, como dito, encontrou-se 430 pesquisas (77 teses e 353 dissertações). A coleta das pesquisas se deu por meio dos Portais Institucionais de cada Programa e das Bibliotecas Universitárias online (pergamum web). Ainda, os dados destes portais foram triangulados com a BDTD, porque em cada página dos portais encontrava-se uma defesa de tese ou dissertação que não constava nas abas vistas anteriormente. Principalmente, com relação às pesquisas defendidas antes ou depois do prazo de término do mestrado e do doutorado (2 e 4 anos). Sendo que a BDTD foi o portal com menor número de teses e dissertações encontradas. A partir da triangulação dos dados é que se chegou ao número de 430 estudos.

Entre os temas mais pesquisados nessas 430 teses e dissertações consta: 88 estudos que abordam os processos e poéticas artísticas (este número poderia ser maior, mas quando o trabalho abordava uma técnica específica como fotografia, desenho, pintura, performance, por exemplo, optou-se por separar as pesquisas em seus respectivos temas); 49 pesquisas que abordam a vida e obras de artistas que foram citados(as) no título; foram encontradas 26 pesquisas voltadas para a fotografia e seus desdobramentos, ainda 26 pesquisas cujo tema principal era o desenho, entre outros temas em menor quantidade.

Nos quatro programas mencionados, há duas linhas de pesquisa voltadas para o ensino e educação: a linha denominada Ensino das artes Visuais, do PPGAV da UDESC e a linha denominada Educação em Artes e Processo de Formação Estética, do PPGAVI da UFPEL. Inicialmente, nas duas linhas foram encontrados 78 estudos, mas a partir dos dois primeiros critérios de seleção, citados no tópico anterior deste artigo, foram selecionados 40 estudos (7 teses e 33 dissertações).

Nestes 40 estudos voltadas para o ensino formal de artes visuais destacaram-se temas como: oficinas realizadas pelos(as) pesquisadores(as); processos artísticos e práticas docentes; prática docente e criação artística dos(as) estudantes e formação de professores(as). Os estudos foram sistematizados a partir da perspectiva teórica e metodológica abordada nos resumos, no título e nas palavras-chave de cada um. Depois, foram realizados paralelos com as disciplinas ofertadas pelos programas, por exemplo: sobre a obrigatoriedade ou não dos estágios nas instituições, sobre a disciplina metodologia da pesquisa e se haviam disciplinas obrigatórias voltadas para o ensino das artes visuais. No quesito oferta de disciplinas, considera-se que faltam disciplinas obrigatórias que enfatizam a formação de professores, mesmo nos Programas que possuem uma linha voltada para o ensino e educação nas artes visuais.

Dentre estas 40 pesquisas, houve um novo recorte de seleção e análise que resultou na seleção de 14 estudos (2 teses e 12 dissertações) voltados, especificamente, para a formação de professores de artes visuais. Sendo que 2 dissertações foram realizadas no PPGAVI da UFPEL e as outras teses e dissertações foram produzidas 
no PPGAV da UDESC. Ou seja, dentre os 430 estudos encontrados, contabiliza-se 14 estudos, quer dizer 3\% da produção total, voltada para a formação de professores.

Dentre estas 14 pesquisas sobre a formação de professores, 11 delas foram orientadas pela mesma professora e 7 delas possuem vínculo com o projeto em rede denominado Observatório da Formação de Professores no âmbito do Ensino de Arte: estudos comparados entre Brasil e Argentina - (OFPEA/BRARG). Também identifica-se ao menos 3 diferentes caminhos de pesquisa: um relacionado a oferta de oficinas para a formação inicial e/ou continuada de professores(as); outro movimento se refere ao pesquisador que se desloca para determinada(s) realidade(s), ali conhece as escolas e/ ou as universidades, realiza entrevistas com os(as) professores(as) e reflete sobre seu objeto de pesquisa; terceiro movimento, quando o foco está nas IES onde ocorre o mapeamento e análise curricular para compreender como ocorre a formação de professores, sob determinada temática investigada e em determinado contexto.

$\mathrm{Na}$ análise dos 14 estudos (2 teses e das 12 dissertações), percebeu-se diversas problemáticas que permeiam a formação de professores, entre elas: as influências internacionais de cunho neoliberal; as reformas intermináveis nas políticas educacionais; a falta de investimento público; a exploração versus a valorização do trabalho docente; a formação aligeirada; como o currículo das instituições repercute aquilo que é legalizado via políticas públicas; a necessidade de se unir enquanto classe de trabalhada da educação, para fazer valer os direitos e cobrar mudanças que venham a contribuir com a educação brasileira, com o ensino de artes visuais e com a formação de professores.

Na continuidade do estudo, explorou-se mais um problema que foi a formação inicial reverberando na pós-graduação. Por isso, voltou-se para as 430 pesquisas, a fim de investigar a formação inicial e a atuação profissional destas 430 pessoas que realizaram as teses e dissertações. A investigação se deu a partir dos Currículos Lattes de cada um(a) dos(as) pesquisadores(as). Como síntese, traz-se os gráficos a seguir.

\footnotetext{
Gráfico 1. Percentual de pessoas que cursaram Licenciatura na formação inicial, conforme preenchido no Currículo Lattes de 430 Mestres(as) e Doutores(as)
}

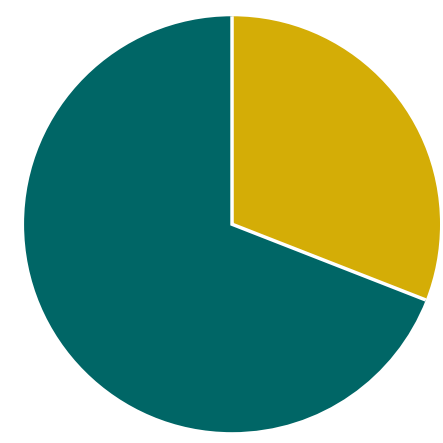

31\% das pessoas cursaram Licenciatura na formação inicial

- $69 \%$ cursaram Bacharelado ou não especificaram 
No Gráfico 01 verifica-se que, de um total de 430 pessoas, 31\% descreveram em seu Currículo Lattes que cursaram licenciatura na graduação. Ainda, 69\% das pessoas descreveram que cursaram bacharelado ou não especificaram qual a modalidade que cursaram, se licenciatura ou bacharelado, apenas preencheram o nome do curso. Mas, a maioria das pessoas que não especificaram, foi porque o curso não possui licenciatura, por exemplo: Publicidade e Propaganda, Arquitetura e Urbanismo, Jornalismo, Comunicação Social, Design Gráfico, Design Digital, Desenho Industrial, Moda, Cinema, Fotografia, Psicologia, Museologia e Biblioteconomia. Aqui também se explicita um problema de preenchimento do Currículo Lattes por um pequeno percentual de mestres(as) e doutores(as) que poderiam especificar no currículo se o curso é bacharelado ou licenciatura.

No Gráfico 02, destaca-se o percentual de pessoas que atuam ou atuaram como professores(as) no ensino formal, conforme preenchido no Currículo Lattes. Onde, $64 \%$ das pessoas preencheram no currículo que atuaram ou atuam como professores(as) no ensino formal, seja na educação básica e/ou no ensino superior. Também, 20\% das pessoas que não possuem experiência no ensino formal, mas possuem experiência no ensino informal, pois ministraram aulas, oficinas, cursou e/ou workshop. E $16 \%$ das pessoas não atuaram no ensino formal nem no ensino informal.

Gráfico 2. Percentual de pessoas que atuam ou atuaram como professores(as) no ensino formal, conforme preenchido no Currículo Lattes de 430 Mestres(as) e Doutores(as)

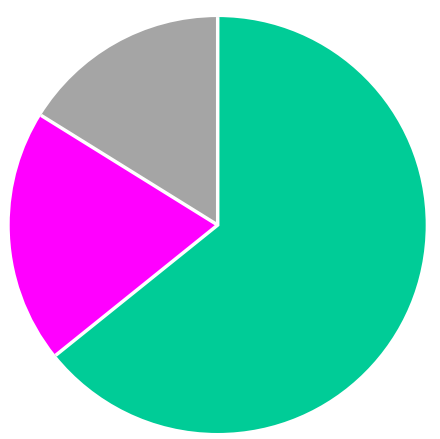

$64 \%$ das pessoas atuaram ou atual no ensino formal

$20 \%$ atuaram ou atuam no ensino informal (aulas, oficinas, cursos, workshop)

$16 \%$ não atuaram no ensino formal nem no ensino informal

Nesta análise, sobre a formação inicial de quem cursou a pós-graduação, concluiu-se que: faz-se necessário aprofundar o debate acerca da formação de professores(as) nos cursos de mestrado e doutorado, porque a maioria das pessoas que concluíram a pós-graduação atuam ou atuaram como professores no ensino formal (64\% das pessoas). Essa porcentagem se amplia para $84 \%$ das pessoas, quando se leva em consideração a atuação no ensino formal e informal. Ao mesmo tempo, a 
maioria das pessoas não cursou licenciatura na formação inicial $(69 \%$ das pessoas cursaram bacharelado ou não especificaram em seu Currículo Lattes).

Agregado a estes dados, também revisou-se os objetivos dos programas de pós-graduação, das quatro instituições abordadas, e em todos os regimentos e regulamentos destaca-se a pesquisa e a qualificação pessoal para o exercício do ensino (docência) ao longo da pós-graduação. Com os documentos oficiais, soma a necessidade de realizar ações concretas que ampliem o debate sobre o ensino e a formação de professores, para o desenvolvimento da práxis docente, independente da linha de pesquisa da pós-graduação em artes visuais, pois a maioria das pessoas que cursaram a pós-graduação Stricto sensu atuaram ou atuam como professores(as).

Um problema de pesquisa, para Saviani (1984), não é apenas uma pergunta onde se pretende responder algo que não se sabe a resposta. Para além disso, traz uma questão que não pode ser ignorada na área. Ao menos cinco dados, levantados ao longo da tese (MÜLLER, 2021) e retomados neste artigo, reverberam a problemática da formação de professores(as) na pós-graduação: 1 - há duas linhas de pesquisa sobre o ensino ou educação nas artes visuais, assim $50 \%$ dos programas investigados não ofertam uma linha voltada para o ensino; 2 - é possível identificar um percentual reduzido de pesquisas voltadas para o ensino e, principalmente, para a formação de professores (3\%); 3 - falta de disciplinas obrigatórias que enfatizam a formação de professores, mesmo nos Programas que possuem uma linha de pesquisa voltada para o ensino e educação nas artes visuais; 4 - a partir da análise dos objetivos dos regimentos e regulamentos dos programas, percebe-se a ênfase dada ao ensino e a pesquisa; 5 - o alto percentual de pessoas que cursam a pós-graduação e atuam como professores, mas não possuem licenciatura.

Por meio destes dados, percebe-se a necessidade de realizar ações concretas, no cotidiano das instituições, que fortaleçam e ampliem os debates e a práxis no ensino de artes visuais e na formação de professores, mesmo para os programas que já possuem linha e projeto de pesquisa na área. Pois, os problemas da pós-graduação repercutem nas teses e dissertações não apenas pela via da identificação e crítica dos problemas, para apontar possíveis soluções, mas também pela via da reprodução destes problemas.

Através da leitura das 14 pesquisas selecionadas (2 teses e 12 dissertações), da identificação de alguns problemas enfrentados na pós-graduação e na perspectiva da Pedagogia Histórico-Crítica, destaca-se a necessidades de: valorizar o ensino das artes visuais que é constantemente atacado; atuar contra a precarização e evitar o desmonte da educação (SAVIANI, 2019); se unir enquanto classe e lutar por valorização profissional; oportunizar para que todas as pessoas tenham acesso à educação e ao capital artístico e cultural (DUARTE, 2006); compreender a função social da arte e assim contribuir para o processo de ensino e aprendizagem; conhecer artes visuais para ensinar e reafirmar a arte como conhecimento, ideologia e como um peculiar trabalho criador (VÀZQUEZ, 1978); identificar as contradições da educação 
nas artes visuais com o intuito de superá-las; identificar os dilemas da formação na pós-graduação para atuar diante das possibilidades, como o dilema da produtividade e qualidade (SAVIANI, 2019), dilema da formação didático-pedagógico e dos conteúdos culturais-cognitivos (SAVIANI, 2009); cobrar do Estado um plano de gestão para investimento público na educação; assim como, reafirmar o papel da escola na transmissão dos conhecimentos e o papel dos(as) professores(as) no ensino e problematização dos saberes.

\section{Considerações}

Diante da realidade atual, em que a pós-graduação sofre com o corte de verbas e bolsas, que enfrenta os desafios de atuar em meio a uma pandemia (nas incertezas do ensino remoto e no retorno ao ensino presencial), ainda, diante dos ataques constantes contra a ciência, a cultura, a arte e as pesquisas, o que os programas podem fazer para contribuir com a formação inicial e continuada de professores?

A pós-graduação pode ampliar e fortalecer a relação com a graduação e a formação inicial de professores; pode criar linhas de pesquisa voltadas para o ensino ou educação nos programas que ainda não possuem; ampliar a oferta de disciplinas obrigatórias que debatem o ensino, a educação e a formação de professores; ofertar o estágio para todo(as) estudantes, independente da linha de pesquisa; realizar projetos de extensão que acolham a comunidade; ampliar o acesso a eventos da área; promover a participação em grupos de estudo, associações, sindicatos e setoriais de artes; fortalecer as associações, as setoriais e os sindicatos para retomar a força da classe de professores ao dizer quantos somos, o que defendemos, o que necessitamos para ampliar as pautas e as ações no embate político, ideológico e educativo; atuar coletivamente para pressionar o governo para ampliar os recursos, cumprir as políticas públicas de formação e valorização de professores; ampliar concursos para nomeação de professores de artes visuais nas escolas e universidades; reforçar a pós-graduação enquanto meio de formar intelectuais comprometidos com a ciência, a pesquisa, a educação, a arte e sociedade.

Além destas, cabe aos programas implementar outras estratégias, por exemplo, ofertar cursos, oficinas e palestras na instituição, ampliar a possibilidade de participação em outros eventos externos à universidade. Ampliar o acesso e a participação nos congressos e eventos como a FAEB, ConFAEB, EnreFAEBs, a ANPAP e a ANPED. Ações que também envolvem verbas, pois são eventos da área, mas que acabam sendo onerosos ao somar a inscrição, submissão de trabalho, gasto com viagens, hospedagem, alimentação, o que impossibilita a participação de muitos estudantes, mesmo para quem recebe uma bolsa na pós-graduação, pois o valor da bolsa está defasado há anos. Por isso, considera-se válido adotar a prática realizada em diferentes eventos, ao longo da pandemia, que foi a transmissão ao vivo (live), com posterior publicação das palestras/conversas no canal do youtube, para que as pessoas possam acessar esse compilado de pesquisas e conhecimentos para além dos Anais publicados. 
Isso resolverá os problemas? Não, porque vive-se em uma sociedade que gira em função da lógica do capital. De acordo com Saviani (2019) e a Pedagogia Histórico-crítica, a meta a ser atingida seria a transformação das relações de produção, no entanto, esta meta não faz parte do horizonte imediato. Então, uma das possibilidades é analisar o contexto, de acordo com cada momento da história, e propor algumas ações estratégicas para atuação.

Neste artigo realizou-se um breve debate sobre a formação de professores na pós-graduação, através das teses e dissertações coletadas nos programas em artes visuais, situados no Sul do Brasil. Considera-se que o trabalho realizado poderá reforçar a necessidade de fortalecer a formação inicial de professores na graduação e a formação continuada de professores na área de artes visuais, através da pós-graduação Stricto sensu e criar estratégias para futuras ações a serem implementadas nas instituições.

Por fim, aproveita-se para reiterar o convite para que as pessoas acessem o site do Observatório da Formação de Professores, pois há diversos artigos, teses, dissertações e dados que podem contribuir para pensar os caminhos a serem trilhados no ensino de artes visuais e para a formação de professores(as). 


\section{Referências}

ALMEIDA, Karla Nazareth Corrêa de. A Pós-graduação No Brasil: História De Uma Tradição Inventada. Tese de Doutorado realizada no Programa de Pós-Graduação em Educação na UNICAMP. Campinas, São Paulo, 2017

DUARTE, Newton. Vigotski e o "aprender a aprender". Críticas às apropriações neoliberais e pós-modernas da teoria vigotskiana. Campinas/SP: Editora Autores Associados, 2006

MARX, Karl; ENGELS, Friedrich. A Ideologia Alemã. Tradução: Luis Cláudio de Castro e Costa. São Paulo, Martins Fontes, 1998

MARX, Karl. O Capital: crítica da economia política. 2.ed.Tradução de Regis Barbosa e Flávio R. Kothe. São Paulo: Nova Cultural, Livro I, Tomo I, 1985

MARX, Karl. O Capital. Livro I, Capítulo VI (inédito). 1ª edição. São Paulo: Livraria Editora Ciências Humanas LTDA, 1978

MÜLLER, Maristela. A Formação de Professores na Pós-graduação de Artes

Visuais no Sul do Brasil. Tese de Doutorado. UDESC: Florianópolis, 2021

SAVIANI, Dermeval. Pedagogia Histórico-Crítica: primeiras aproximações.

Campinas, SP: autores Associados, 2013

Escola e Democracia. Polêmicas do Nosso Tempo. Campinas, SP: Autores Associados, 2018

Pedagogia Histórico-Crítica, quadragésimo ano, novas

aproximações. Campinas, SP: Autores Associados, 2019

Educação: Do Senso Comum à Consciência Filosófica. 4aㅡ Ed. São Paulo: Cortez Editora: Autores Associados, 1984

Formação de professores: aspectos históricos e teóricos do problema no contexto brasileiro. Revista Brasileira de Educação, v. 14, n. 40, p. 143155, 2009. Disponível em: https://www.sinte-sc.org.br/files/1081/Texto\%202\%20\%20 For\%20docente\%20aspectos\%20hist\%20Saviani.pdf. Acesso em: 21 de maio de 2021 
VÀZQUEZ, Adolfo Sánchez. As idéias estéticas de Marx. Rio de Janeiro: Editora Civilização Brasileira S. A e Editora Paz e Terra, 1968.

Submetido em 30/09/2021.

Aprovado em 01/12/2021. 